\title{
Single vs dual rod constructs in early onset scoliosis treated with magnetically controlled growing rods
}

\author{
Wiktor Urbański, ${ }^{1,2, A-D}$, Stewart Tucker ${ }^{2, A, E, F}$, Thomas Ember ${ }^{2, A, C, F}$, Ramesh Nadarajah ${ }^{2, C, F}$ \\ ${ }^{1}$ Department of Neurosurgery, Wroclaw Medical University, Poland \\ ${ }^{2}$ Department of Orthopedic and Spine Surgery, Great Ormond Street Hospital, London, United Kingdom \\ A - research concept and design; $B$ - collection and/or assembly of data; $C$ - data analysis and interpretation; \\ $D$ - writing the article; $E$ - critical revision of the article; $F$ - final approval of the article
}

\section{Address for correspondence \\ Wiktor Urbański \\ E-mail: urbanski.wiktor@gmail.com}

\section{Funding sources}

None declared

Conflict of interest

None declared

Received on August 16, 2018

Reviewed on September 6, 2018

Accepted on August 8, 2020

Published online on October 16, 2020

Cite as

Urbański W, Tucker S, Ember T, Nadarajah R. Single vs dual rod constructs in early onset scoliosis treated with magnetically controlled growing rods. Adv Clin Exp Med. 2020;29(10):1169-1174. doi:10.17219/acem/126289

DOI

10.17219/acem/126289

\section{Copyright}

Copyright by Author(s)

This is an article distributed under the terms of the

Creative Commons Attribution 3.0 Unported (CC BY 3.0)

(https://creativecommons.org/licenses/by/3.0/)

\begin{abstract}
Background. Non-invasive distractions of recently introduced magnetically controlled growing rods (MGCRs) spare multiple operations in the surgical treatment of early onset scoliosis (EOS). Since the costs of the implants are high, concerns have been raised regarding cost-effective, optimal but safe MGCR options: single or dual constructs.
\end{abstract}

Objectives. To report deformity control, spinal growth and complication incidence in EOS patients treated with MCGR single- or dual-rod constructs.

Material and methods. The study involved 47 patients with MCGRs inserted at Great Ormond Street Hospital, London (UK) in 2013-2014, who were followed up for at least 1 year. In 32 patients, T1-S1 distances, and coronal and sagittal curves were measured on preoperative and postoperative $X$-rays, and at a one-year follow-up. All complications were recorded. The patients were analyzed in 2 groups: those with single-rod constructs (24 patients) and those with dual-rod constructs (23 patients).

Results. Comparing postoperative with one-year follow-up measurements, T1-S1 length increase was better in the dual-rod group (3.29\%) than in the single-rod group (0.34\%) $(p=0.031)$. In the whole series, mean scoliosis magnitude dropped by $27.5 \%$ at the one-year follow-up. The dual-rod group showed better mean curve correction: $36.5 \%$ compared to $15.3 \%$ in the single-rod group ( $p=0.0076)$. Overall, $34.04 \%$ of the patients had complications: $45.8 \%$ in the single-rod group and 30.4\% in the dual-rod group $(p=0.0413)$. Metalwork failure was observed in 8 patients, lengthening problems in 5 and wound infections in 2; there was also 1 case of proximal junctional kyphosis (PJK). Preoperative hyperkyphosis was associated with more complications (75\%, $p=0.037$ ), most of which were metalwork failure (41.6\%).

Conclusions. The MCGRs are efficient at controlling EOS; however, the complication rate is high, particularly in single-rod constructs. The use of dual-rod constructs allows for better curve control, greater T1-S1 length increase and a lower complication rate.

Key words: early onset scoliosis, magnetically controlled growing rod, dual rods, spinal growth 


\section{Introduction}

Patients with progressive spinal deformities which cannot be controlled with conservative measures are usually candidates for surgical treatment. The goal of the treatment of scoliosis in an immature, growing spine - early onset scoliosis (EOS) - is not only to control deformity progression but also to allow the growth of the spine. It is particularly important in children below the age of 5 years, since normal growth of the thoracic spine ensures the necessary development of the chest and lungs. ${ }^{1}$

In order to meet these goals, growth-friendly systems of spinal implants were developed. Three approaches are present in clinical practice: growth guidance, tethering and the most popular: distraction-based systems. ${ }^{2}$ Distraction-based systems are efficient at deformity control, concomitantly preserving spinal growth; however, the method has a discouragingly high complication rate, and multiple surgical distractions are needed to follow spinal growth. ${ }^{3}$

The introduction of magnetically controlled growing rods (MCGRs) allowing for noninvasive distractions raised hopes of reducing complications and avoiding multiple operations associated with standard growing rods. ${ }^{4}$ The method is fairly new, and the efficiency of the system in terms of deformity control, spinal growth and complication rate has not yet been decisively established. The high cost of the method is another concern. Therefore, questions have been raised about whether the application of a single rod might be a safe, efficient and cost-effective clinical approach.

The aim of this observational study was to report spinal growth, coronal curve control and the complication rate in EOS patients treated with dual or single MCGR constructs.

\section{Material and methods}

The study involved 47 patients with diagnosed progressive EOS who underwent MCGR insertion between 2013 and 2014 in the Spinal Unit of Great Ormond Street Hospital, London (UK). All the patients were followed up for at least 1 year (range: $12-30$ months). The study group included 18 girls and 14 boys with a mean age of 8.8 years (range: 2.5-11 years) at the time of the surgery. Thirty-two patients had all the measurements conducted on preoperative and follow-up X-rays. The remaining 15 patients missed a follow-up X-ray or the X-ray quality was insufficient for detailed and precise measurements; therefore, those patients were excluded from the analysis. In the series, all types of EOS were included (idiopathic, neuromuscular, congenital, and syndromic). All distractions were performed in the outpatient clinic with a mean distraction frequency of 3 months.

The magnitude of coronal curves and T1-S1 distances were measured on the X-rays obtained in a vertical position, prior to the operation, immediately after the operation (during the hospital stay) and 1 year from the operation. The initial sagittal profile was assessed; thoracic kyphosis (measured between the end plates of $\mathrm{T} 2$ and $\mathrm{T} 12$ ) above $50^{\circ}$ was considered a kyphotic profile; $20-50^{\circ}$ was considered normal; and below $20^{\circ}$ was considered lordotic (hypokyphotic).

All complications were recorded and divided into 4 groups: metalwork failure (rod breakage, fixation failure - a screw/hook dislodging or loosening), distraction issues (pin breakage, unknown), infections, and proximal junction kyphosis (PJK).

The patients were analyzed in 2 groups. The singlerod construct group contained 24 patients and the dual-rod construct group included 23 patients. Data and comparisons between the groups were statistically analysed using Student's t-test. In cases of non-homogeneity of variance and/or non-normal distribution ( $p>0.05)$, the Mann- Whitney U test was used. The Mann-Whitney U value was used when groups had fewer than 20 samples, while the $Z$ value was used when one of the groups had $\geq 20$ samples. A p-value less than 0.05 was considered statistically significant.

\section{Results}

\section{T1-S1 distance}

The average T1-S1 distance increased in the whole series of patients. The initial increase in the distance after surgery (preoperative compared to immediately postoperative) was similar in the single-rod group $(10.7 \pm 8.42 \%)$ and the dual-rod group $(10.44 \pm 6.51 \%)$ ( $\mathrm{p}=0.463)$. Slightly better growth was observed in the dual-rod group, comparing the mean preoperative $\mathrm{T} 1-\mathrm{S} 1$ distance to 1 year after the operation; the single-rod group showed $11.03 \pm 8.03 \%$, while the dual-rod group showed $14.03 \pm 8.04 \%(\mathrm{p}=0.316)$ growth. Comparing initial postoperative T1-S1 lengths with one-year postoperative lengths, substantially greater increases were obtained in the dual-rod group (3.29\%) than in the single-rod group (0.34\%) ( $\mathrm{p}=0.031$; Fig. 1).

An EOS etiology analysis showed the greatest increase in the T1-S1 distance in syndromic patients (16.06\%) ( $p=0.049)$ and neuromuscular patients $(14.93 \%)$ $(\mathrm{p}=0.042)$. The lowest growth was observed in idiopathic patients (10.58\%) and those with congenital deformities (7.12\%) (Fig. 2).

\section{Deformity control}

In the whole series, the initial postoperative mean scoliosis curve magnitude dropped by $32.4 \%$, then in 1 year it increased by $7.2 \%$, resulting in an overall curve reduction of $27.5 \%$ at the end of the follow-up. The dual-rod group showed better initial curve correction 


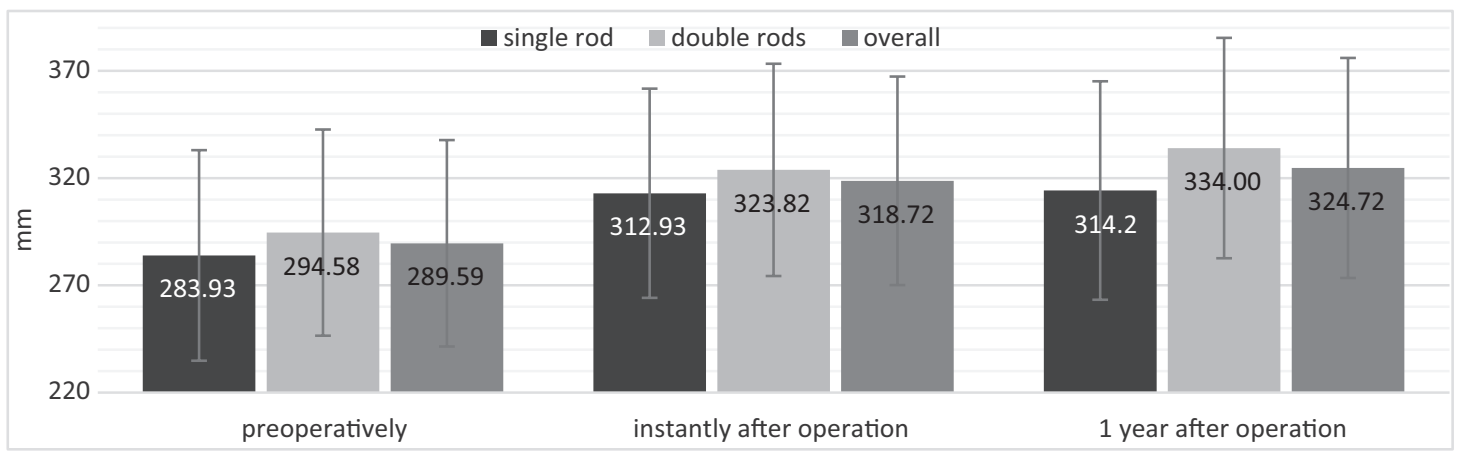

Fig. 1. The mean $\mathrm{T} 1-\mathrm{S} 1$ values $[\mathrm{mm}]$ in the single- and double-rod groups

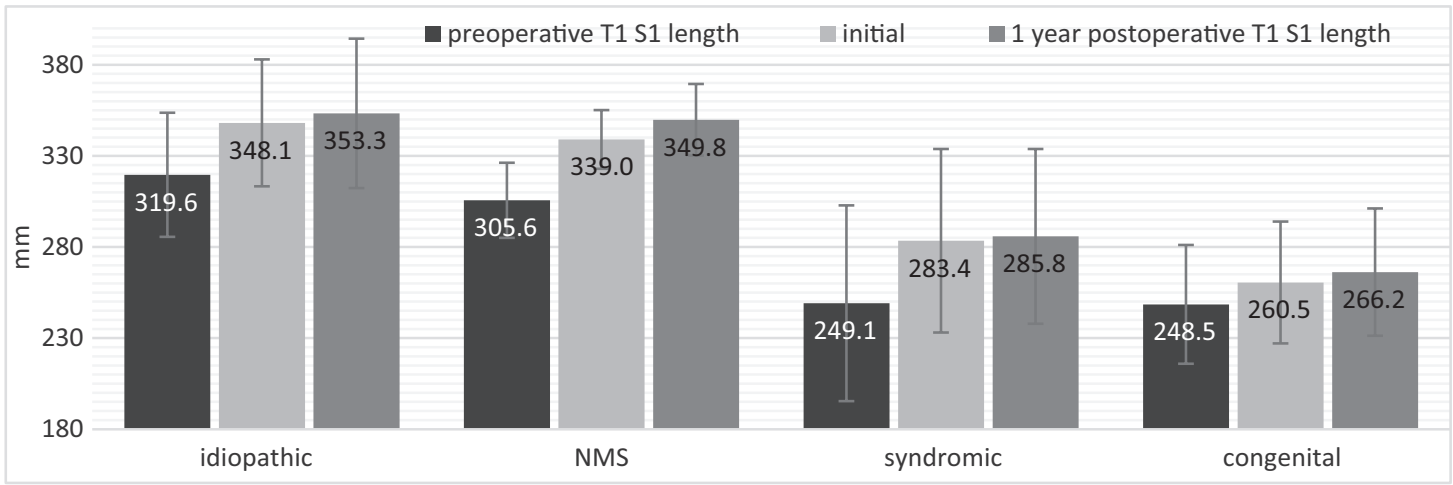

Fig. 2. The mean $\mathrm{T} 1-\mathrm{S} 1$ values $[\mathrm{mm}]$ in terms of spinal deformity etiology
$(40.08 \%)$ than the single-rod group $(21.8 \%)(\mathrm{p}=0.004)$. At the one-year follow-up, the mean Cobb angle had increased by $5.8 \%$ in the dual-rod group and by $8.3 \%$ in the single-rod group ( $\mathrm{p}=0.722)$. At the end of the follow-up, a $15.3 \%$ reduction in the coronal curve was observed in the single-rod group and $36.5 \%$ in the dual-rod group ( $\mathrm{p}=0.0076$ ) (Fig. 3 ).

Patients with neuromuscular scoliosis had the greatest curve correction, followed by those with idiopathic and syndromic scoliosis, with the weakest effect in patients with congenital scoliosis; however, no statistical significance was observed (Fig. 4).

\section{Complications}

As shown in Table 1, in the whole series of 47 patients, 17 complications (36.17\%) were observed in 16 patients (34.04\%). Metalwork failure was the most frequent complication, observed in 8 patients (17.02\%). Two patients (4.25\%) had deep wound infections (both revised). Problems with MCGR lengthening were observed in 5 cases (10.63\%). Proximal junction kyphosis was observed in 1 child, but no revision was necessary during follow-up. Overall, 13 revisions were performed: the 2 infections, 3 distraction issues and 8 metalwork failures.

Table 1. Complications and patient characteristics

\begin{tabular}{|c|c|c|c|c|c|c|}
\hline \multicolumn{2}{|c|}{$\begin{array}{c}\text { Complications } n=17 \\
(36.17 \%)\end{array}$} & Metalwork failure & Lengthening issues & Infection & PJK & General \\
\hline \multirow{4}{*}{ Etiology } & idiopathic $(n=20)$ & $2(10 \%)$ & $3(15 \%)$ & $1(5 \%)$ & $1(5 \%)$ & $7(35 \%)$ \\
\hline & neuromuscular $(n=10)$ & $1(10 \%)$ & $1(10 \%)$ & $1(10 \%)$ & 0 & $3(30 \%)$ \\
\hline & congenital $(n=6)$ & $2(33.3 \%)$ & 0 & 0 & 0 & $2(33.3 \%)$ \\
\hline & syndromic $(n=11)$ & $4(36.4 \%)$ & $1(9.1 \%)$ & 0 & 0 & $5(45.5 \%)$ \\
\hline \multirow{3}{*}{ Sagittal profile } & kyphotic $(n=12)$ & $5(41.6 \%)$ & $2(16.6 \%)$ & $1(8.3 \%)$ & $1(8.3 \%)$ & $9(75 \%)$ \\
\hline & lordotic $(n=15)$ & $1(6.6 \%)$ & $3(20 \%)$ & 0 & 0 & $4(26.6 \%)$ \\
\hline & normal $(n=20)$ & $3(15 \%)$ & 0 & $1(5 \%)$ & 0 & $4(20 \%)$ \\
\hline \multirow{2}{*}{ Rod construct } & single rod $(n=24)$ & $5(20.8 \%)$ & $3(12.5 \%)$ & $1(4.2 \%)$ & $2(8.3 \%)$ & $11(45.8 \%)$ \\
\hline & dual rod $(n=23)$ & $4(17.4 \%)$ & $2(8.7 \%)$ & $1(4.34 \%)$ & 0 & $7(30.4 \%)$ \\
\hline \multirow{2}{*}{ Curve magnitude } & $<70^{\circ}(\mathrm{n}=25)$ & $3(12 \%)$ & $3(12 \%)$ & $1(4 \%)$ & $1(4 \%)$ & $8(32 \%)$ \\
\hline & $>70^{\circ}(n=22)$ & $6(27.3 \%)$ & $2(9 \%)$ & $1(4.5 \%)$ & 0 & $9(40.9 \%)$ \\
\hline
\end{tabular}

PJK - proximal junctional kyphosis. 


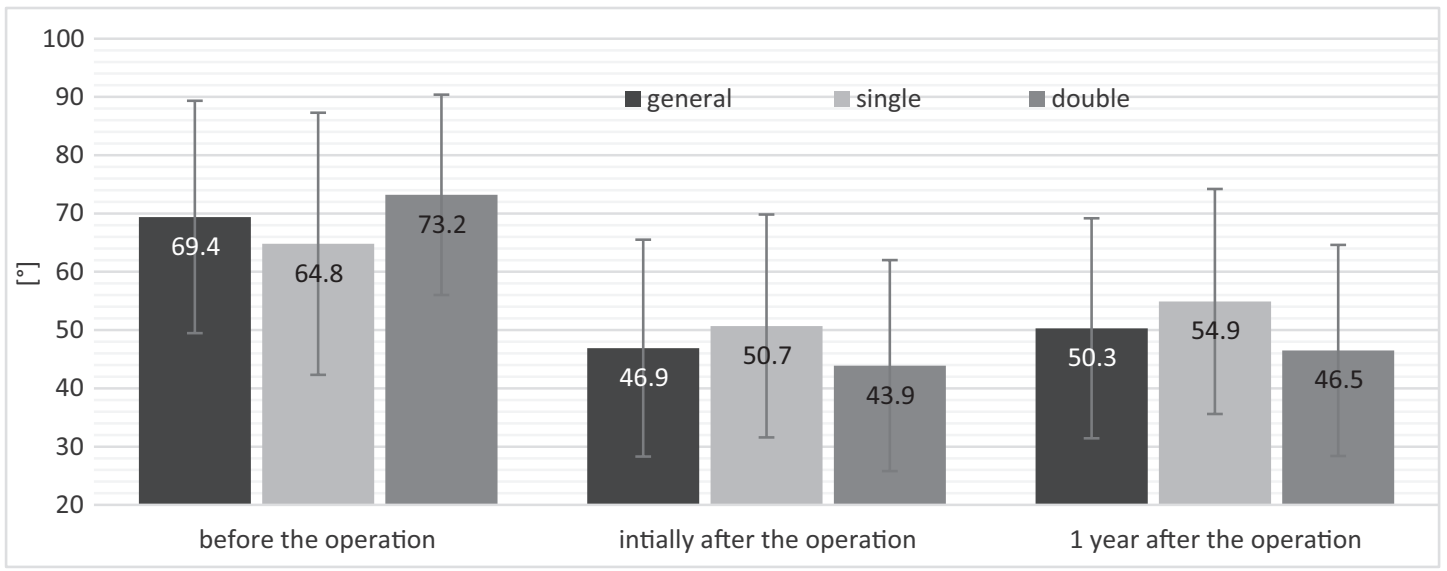

Fig. 3. Average Cobb angle in all groups

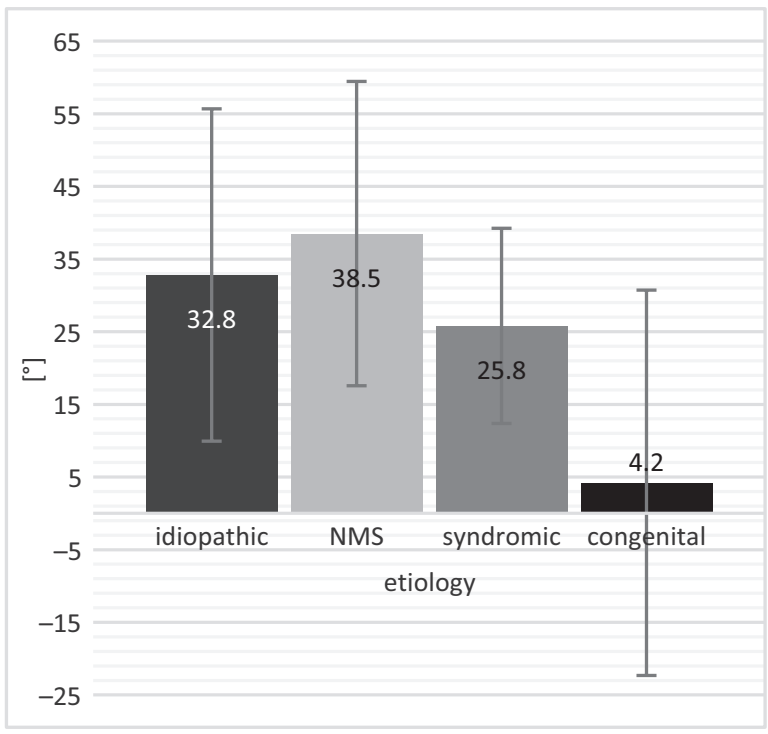

The highest rate of complications was observed in the 11 patients with syndromic scoliosis (45.5\%), most of which (36.6\%) were metalwork issues. Preoperative hyperkyphosis tended to produce a high rate of complications. Among the 12 hyperkyphotic patients, 9 (75\%) had complications; most of these were metalwork failures (41.6\%) (Fig. 5). These results proved to be statistically significant $(\mathrm{p}=0.037$ ).

There was a higher overall complication rate in the single$\operatorname{rod}(45.8 \%)$ than in dual-rod $(30.4 \%)$ constructs ( $\mathrm{p}=0.0413)$. Metalwork problems, PJK and rod distraction issues occurred more frequently in single-rod construct patients. The single- and dual-rod groups each had 1 case of infection.

Curve severity was not found to contribute to the complication rate; however, a slightly elevated frequency of metalwork failure was present in patients with scoliosis above $70^{\circ}(\mathrm{p}=0.195)$.

Fig. 4. Curve magnitude change in relation to etiology
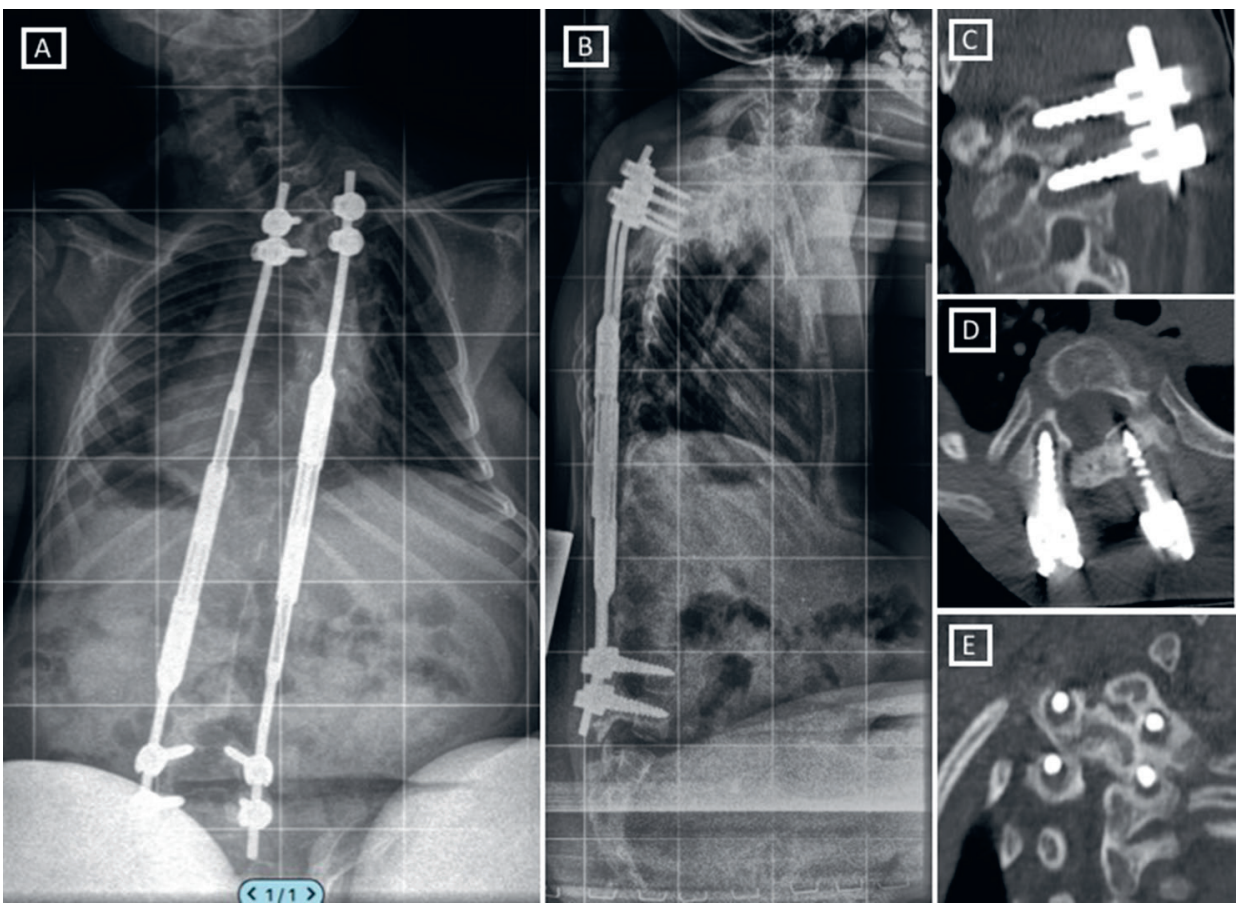

Fig. 5. Loss of proximal fixation of MGCR. Plain whole spine $X$-rays in posteroanterior (A) and lateral (B) projections. The $\mathrm{CT}$ images of loosened screws in sagittal (C), axial (D) and coronal (E) views 


\section{Discussion}

The popularity of MCGRs is continuously growing, mainly due to the major advantage of avoiding open distractions. Primary reports concluded that MCGRs are a safe and effective option for the treatment of progressive pediatric scoliosis. ${ }^{4}$ However, the presented series were rather small in number, and as more observations emerged, more doubts were raised, particularly regarding the incidence of complications, which appeared to be higher than previously considered. ${ }^{5-8}$

In our retrospective analysis of a consecutive series of patients treated with MCGRs, we observed overall good curve control and spinal growth; however, better growth of the T1-S1 distance and better curve control was noticed in the dual-rod group. The incidence of complications was generally high in the whole series (34\%), but it was particularly high in patients with initial hyperkyphosis (75\%) and those with single-rod constructs (45\%), as opposed to dual-rod constructs (30\%). The complication rate was comparable in all types of scoliosis, and we did not find any correlation between the initial coronal curve magnitude and the complication rate.

This study has several limitations. It is only a one-year retrospective follow-up of a heterogeneous group of EOS patients treated with MCGRs; however, the series analyzed is rather large in comparison to other reports available in the literature. A comparable cohort to ours was presented only by Dannawi et al. ${ }^{9}$

Several other papers have reported similar MCGR results to ours: overall good coronal curve control and T1-S1 distance growth.,10-12 Comparisons of traditional (TGRs) vs magnetic (MCGR) growing rods demonstrated similar ability to control major curve as well as to obtain good T1-S1 distance growth5, but the advantage of MCGRs over TGRs is an avoidance of multiple planned operations for the rod distractions.

The high costs of MCGRs and the lower invasiveness of the operation might have motivated surgeons to insert constructs based on single rods, but the data presented suggests that this solution results in lower spinal growth $(11 \%$ in single-rod compared to $14 \%$ in dual-rod constructs) and inferior scoliosis correction (by $15 \%$ and $36.5 \%$, respectively). Akbarnia et al. and Dannawi et al. both reported minor improvement in T1-S1 distance growth in patients with single rods compared to those with dual rods, but in our series, the differences were more pronounced $\left(65-55^{\circ}\right.$ compared to $\left.73-46.5^{\circ}\right)$ than in the studies by Akbarnia et al. $\left(68-36^{\circ}\right.$ compared to $\left.56-29^{\circ}\right)$ and by Dannawi et al. $\left(67-44^{\circ} \mathrm{com}-\right.$ pared to $\left.70-40^{\circ}\right) .{ }^{9,10}$ It appears that, like TGRs, single rod growing constructs entail more frequent complications, particularly rod breakage and fixation problems. ${ }^{12,13}$

Surgical treatment of EOS is known to have significant complication rates, especially due to infection and metal/ work failures. According to recent reports comparing TGRs and MCGRs, there is lower incidence of infection in MCGRs. ${ }^{7,14}$ Reports regarding metalwork problems are more inconsistent, showing lower, ${ }^{13}$ similar $^{5}$ or higher complication rates in $\mathrm{MCGR}^{7}$ compared to TGRs. The MCGR patients undergo fewer surgical procedures than TGR patients, but the incidence of unplanned surgical revisions has been reported as similar in the 2 groups. ${ }^{5}$ The cohorts in the studies by Teoh et al. and Akbarnia et al. included a significant number of single-rod constructs, and the majority of patients had the first generation of MCGRs implanted. ${ }^{7,10}$ These 2 facts may contribute to poorer curve control and spinal growth results, and to the higher complication rate.

The background (etiology) of a deformity often influences treatment decisions and may affect treatment outcomes. ${ }^{15}$ In the present study, complications most frequently occurred in syndromic scoliosis, mainly metalwork failure. In this group, a significant number of patients consisted of osteogenesis imperfecta (OI) patients with very poor bone quality; 1 patient experienced fixation dislodgment twice.

We observed that the preoperative spinal sagittal profile (unlike the preoperative magnitude of the primary coronal curve) may affect the complication rate. In our results, hyperkyphosis significantly elevates the risk of metalwork failure - nearly half of our hyperkyphotic patients had this complication. These observations are consistent with those made with TGRs. ${ }^{3,16}$

Despite being the most modern surgical solution for progressing pediatric spinal deformities, MCGR treatment has limitations. Some of them are similar to those noted with TGRs, particularly metalwork problems and distraction issues. Since there are many similarities between TGRs and MCGRs, lessons learned from TGRs should be transferred to clinical practice with MCGRs; after all, it is still a distraction-based growing system. Nonetheless, we are far from an ideal solution and there is a strong need for further research with a special focus on reducing complications.

\section{Conclusions}

The MCGRs are efficient in controlling deformities in EOS and provide good spinal growth. The complication rate remains high, as in other surgical methods of EOS treatment; however, the use of dual-rod constructs can decrease the complication rate in comparison to single-rod constructs. Particular caution is required in cases of hyperkyphosis, since these patients are more inclined to develop metalwork problems. Dual-rod constructs provide better curve control, greater T1-S1 length growth and lower complication rates than single-rod constructs.

\section{ORCID iDs}

Wiktor Urbański (D) https://orcid.org/0000-0003-3784-0233

Stewart Tucker (1D https://orcid.org/0000-0001-6999-0098

Thomas Ember (D) https://orcid.org/0000-0002-4011-6089

Ramesh Nadarajah (1) https://orcid.org/0000-0001-9895-9356 


\section{References}

1. Dimeglio A, Canavese F, Bonnel F. Normal growth of the spine and thorax. In: Akbarnia BA, Yazici M, Thompson GH, et al, eds. The Growing Spine: Management of Spinal Disorders in Young Children. $2^{\text {nd }}$ ed. Berlin-Heidelberg, Germany: Springer-Verlag; 2016.

2. Yang S, Andras LM, Redding GJ, Skaggs DL. Early-onset scoliosis: A review of history, current treatment, and future directions. Pediatrics. 2016;137(1). doi:10.1542/peds.2015-0709

3. Odenta T, Ilharreborde B, Miladi L, et al; Scoliosis Study Group (Groupe d'étude de la scoliose); French Society of Pediatric Orthopedics (SOFOP). Fusionless surgery in early-onset scoliosis. Orthop Traumatol Surg Res. 2015;101(6 Suppl):S281-S288.

4. Cheung KM, Cheung JP, Samartzis $D$, et al. Magnetically controlled growing rods for severe spinal curvature in young children: A prospective case series. Lancet. 2012;379(9830):1967-1974.

5. Akbarnia BA, Pawelek JB, Cheung KM, et al; Growing Spine Study Group. Traditional growing rods vs magnetically controlled growing rods for the surgical treatment of early-onset scoliosis: A casematched 2-year study. Spine Deform. 2014;2(6):493-497.

6. Teoh KH, Winson DM, James SH, et al. Magnetic controlled growing rods for early-onset scoliosis: A 4-year follow-up. Spine J. 2016;16 (4 Suppl):S34-S39.

7. Teoh KH, Winson DM, James $\mathrm{SH}$, et al. Do magnetic growing rods have lower complication rates compared with conventional growing rods? Spine J. 2016;16(4 Suppl):S40-S44.

8. Figueiredo N, Kananeh SF, Siqueira HH, Figueiredo RC, Al Sebai MW. The use of magnetically controlled growing rod device for pediatric scoliosis. Neurosciences. 2016;21(1):17-25.
9. Dannawi Z, Altaf F, Harshavardhana NS, El Sebaie H, Noordeen $\mathrm{H}$. Early results of a remotely-operated magnetic growth rod in earlyonset scoliosis. Bone Joint J. 2013;95-B(1):75-80.

10. Akbarnia BA, Cheung K, Noordeen $\mathrm{H}$, et al. Next generation of growthsparing techniques: Preliminary clinical results of a magnetically controlled growing rod in 14 patients with early-onset scoliosis. Spine (Phila Pa 1976). 2013;38(8):665-670.

11. Hickey BA, Towriss C, Baxter G, et al. Early experience of MAGEC magnetic growing rods in the treatment of early onset scoliosis. Eur Spine J. 2014;23(Suppl 1):S61-S65.

12. La Rosa G, Oggiano L, Ruzzini L. Magnetically controlled growing rods for the management of early-onset scoliosis: A preliminary report. J Pediatr Orthop. 2017;37(2):79-85.

13. Xu G-J, Fu X, Tian P, Ma J-X, Ma X-L. Comparison of single and dual growing rods in the treatment of early onset scoliosis: A meta-analysis. J Orthop Surg Res. 2016;11:80.

14. Polly DW, Ackerman SJ, Schneider K, Pawelek JB, Akbarnia BA. Cost analysis of magnetically controlled growing rods compared with traditional growing rods for early-onset scoliosis in the US: An integrated health care delivery system perspective. Clinicoecon Outcomes Res. 2016;8:457-465.

15. Cunin V. Early-onset scoliosis: Current treatment. Orthop Traumatol Surg Res. 2015;101(1 Suppl):S109-S118.

16. Schroerlucke SR, Akbarnia BA, Pawelek JB, et al; Growing Spine Study Group. How does thoracic kyphosis affect patient outcomes in growing rod surgery? Spine (Phila Pa 1976). 2012;37(15):1303-1309. 